\title{
Prolapse of Orbital Fat through the Inferior Orbital Fissure: Description, Prevalence, and Assessment of Possible Pathologic Associations
}

\author{
(D) P.M. Bunch, ${ }^{\text {DK. Buch, and }}$ (D) H.R. Kelly
}

\begin{abstract}
BACKGROUND AND PURPOSE: A few patterns of orbital fat prolapse have been described. Some are associated with disease, and others may mimic a neoplasm. We have observed prolapse of orbital fat into the infratemporal fossa via the inferior orbital fissure on MR imaging. The clinical relevance of this finding, if any, is unknown. The purposes of this study were to describe the MR imaging appearance of orbital fat prolapse through the inferior orbital fissure, to estimate the prevalence of this finding, and to assess possible pathologic associations.
\end{abstract}

MATERIALS AND METHODS: For this retrospective study of 228 orbital MR imaging examinations, 3 neuroradiologists independently assessed the presence of prolapse on high-resolution T1-weighted images. Discrepancies were resolved by consensus, and interobserver agreement was calculated. Patient demographics, indications for imaging, and pertinent clinical history were recorded. One-way analysis of variance and the Fisher exact test were used to assess possible associations between prolapse and specific patient characteristics.

RESULTS: Orbital fat prolapse through the inferior orbital fissure was observed in 20/228 patients (9\%). This finding was unilateral in 11 patients (55\%) and bilateral in 9 patients (45\%). There was no significant association with age, sex, obesity, Graves disease, hypercortisolism, prior orbital trauma, proptosis, or enophthalmos. Interobserver agreement was $90 \%$.

CONCLUSIONS: Prolapse of orbital fat into the infratemporal fossa via the inferior orbital fissure is a relatively common finding on orbital MR imaging that has no identified pathologic association. Neuroradiologists should recognize this finding so as not to report it as pathologic.

S everal patterns of orbital fat prolapse have been previously described, ${ }^{1-4}$ some of which are clinically relevant. Intracranial fat prolapse has been associated with optic nerve compression in thyroid eye disease. ${ }^{1}$ Subconjunctival fat prolapse can mimic a neoplasm ${ }^{2}$; conversely, orbital lymphoma may mimic subconjunctival fat prolapse. ${ }^{5}$ Also, some data suggest an association between subconjunctival fat prolapse and thyroid eye disease. ${ }^{6}$

Received March 20, 2019; accepted after revision May 27.

From the Department of Radiology (P.M.B.), Wake Forest School of Medicine, Winston Salem, North Carolina; Department of Radiology (K.B., H.R.K.), Massachusetts General Hospital, Harvard Medical School, Boston, Massachusetts; and Department of Radiology (H.R.K.), Massachusetts Eye and Ear, Harvard Medical School, Boston, Massachusetts.

A previous and more primitive version of this work was presented as an electronic scientific poster at: Annual Meeting of the American Society of Head and Neck Radiology, September 26-30, 2018; Savannah, Georgia. This article contains additional data and analyses not included in the previous electronic scientific presentation.

Please address correspondence to Paul M. Bunch, MD, Department of Radiology, Wake Forest School of Medicine, Medical Center Blvd, Winston Salem, NC 27157; e-mail: paul.m.bunch@gmail.com; @pbunchmd

http://dx.doi.org/10.3174/ajnr.A6113
Not infrequently, orbital fat prolapse may be posttraumatic. ${ }^{3,4}$ Orbital fat prolapse may but does not necessarily occur in the setting of proptosis. In a small study of patients with proptosis with excess orbital fat, ${ }^{7}$ obesity, Graves disease, and Cushing syndrome were found to represent the underlying disease processes.

We have observed prolapse of the orbital fat into the infratemporal fossa via the inferior orbital fissure on MR imaging. The prevalence of this finding and the clinical relevance, if any, are unknown. We hypothesized that this finding falls within the range of normal anatomic variations and is not associated with orbital disorders or systemic diseases with orbital manifestations.

The purposes of this study were to describe the MR imaging appearance of orbital fat prolapse through the inferior orbital fissure, to estimate the prevalence of this finding, and to test our hypothesis that this finding represents a normal variant by assessing possible pathologic associations with aging, obesity, Graves disease, hypercortisolism (eg, Cushing disease, exogenous steroids), prior orbital trauma, proptosis, and enophthalmos. 

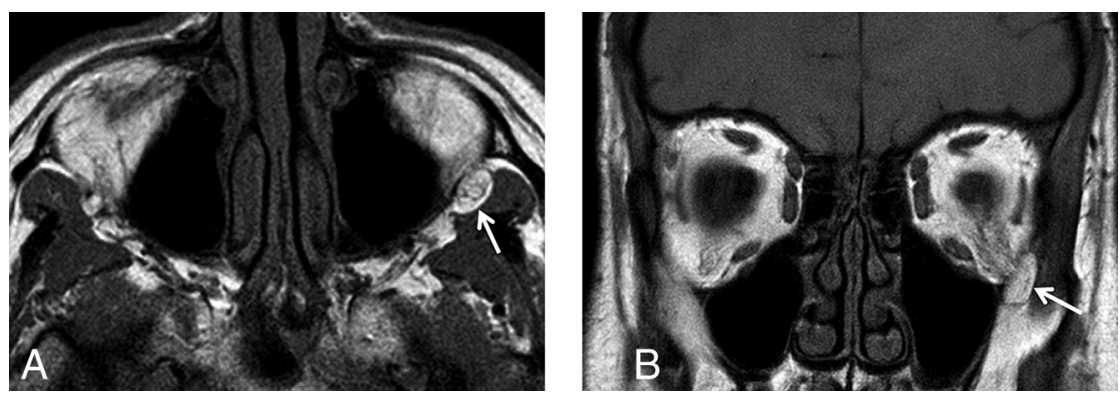

FIG 1. Axial $(A)$ and coronal $(B)$ T1-weighted images demonstrate prolapse of the left orbital fat (white arrows) into the left infratemporal fossa via the left inferior orbital fissure.
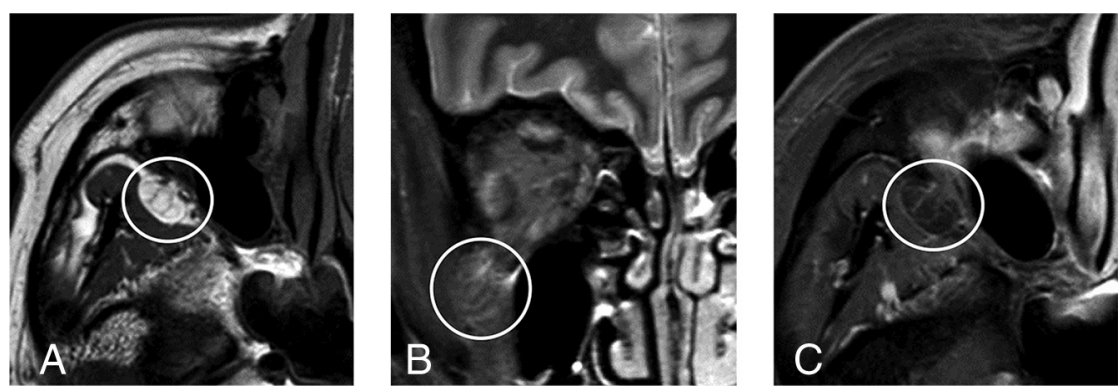

FIG 2. Axial T1-weighted image (A) demonstrates septa within the prolapsed orbital fat (circle). Coronal STIR image $(B)$ demonstrates faintly increased fluid signal associated with the prolapsed orbital fat (circle). Axial gadolinium-enhanced T1-weighted image with fat suppression (C) demonstrates faint enhancement associated with the prolapsed orbital fat (circle).

\section{MATERIALS AND METHODS \\ Subjects}

For this retrospective, Health Insurance Portability and Accountability Act-compliant, institutional review board-approved study, all orbital MR imaging examinations performed at Massachusetts Eye and Ear between January 1, 2017, and August 1, 2017, were reviewed $(n=324)$ by 3 neuroradiologists. Inclusion criteria were the following: 1) a high-resolution axial T1-weighted sequence through the orbits without gadolinium contrast, and 2) no prior orbital operation. Examinations were excluded if an orbital MR imaging examination had already been included in the study cohort for the same patient or the diagnostic assessment was precluded by severe motion artifacts or other artifact degradation. A total of 228 orbital MR imaging examinations satisfied these criteria and formed the study cohort.

\section{Medical Record Review}

Basic patient characteristics including age, sex, and body mass index were recorded. Pertinent medical history was also recorded, including a history of orbital trauma and endocrinopathies, including Graves disease and Cushing syndrome. A targeted review of patient medications was also performed, including the use of oral steroid medications.

\section{Image Acquisition}

All orbital MR imaging examinations were performed on a 3T scanner (Achieva; Philips Healthcare, Best, the Netherlands) using an 8-channel head coil (SENSE Flex M coil; Philips Healthcare). Although there was some variability in the individual sequences included in each orbital MR imaging examination related to the retro- spective nature of this study, the typical examination included sagittal $\mathrm{T} 1$, axial DWI, axial T2, and axial T1 gadoliniumenhanced images of the brain as well as high-resolution axial T1, coronal T1, coronal STIR, and coronal fat-suppressed T1 gadolinium-enhanced images of the orbits. For high-resolution sequences, the slice thickness was 3-mm and the acquisition matrix ranged from $300 \times 300$ to $415 \times 415$.

\section{Reader Assessment}

After a training session based on 10 orbital MR imaging examinations that were not included in this study cohort, 3 fellowship-trained neuroradiologists ( 8,3 , and 2 years' subspecialty expertise) independently reviewed the high-resolution axial T1-weighted images from the 228 included orbital MR imaging examinations using the PACS of our institution. When present, the high-resolution coronal T1weighted images were also reviewed.

Each neuroradiologist recorded the presence or absence of orbital fat prolapse for each eye in all patients. The recorded results were compared, and discrepancies were resolved by a consensus review.

Prolapse was defined as present when a discrete, rounded focus of fat signal intensity could be identified as both distinguishable from the normal infratemporal fossa fat and contiguous with the normal orbital fat via the inferior orbital fissure (Fig 1). When prolapse was present, 1 fellowship-trained neuroradiologist performed a long-axis measurement of the prolapsed fat on highresolution T1 images. The same neuroradiologist also evaluated the prolapsed fat for associated septa on T1-weighted images, fluid signal on STIR images, and enhancement on gadoliniumenhanced T1-weighted images with fat suppression (Fig 2). Additionally, a different neuroradiologist measured the perpendicular distance from the anterior margin of each globe to the interzygomatic line with the upper limit of normal defined as $21 \mathrm{~mm}^{7}$ and the lower limit of normal defined as $12 \mathrm{~mm}^{8}$

\section{Statistical Analysis}

Absolute and relative frequencies are reported for categoric variables and interobserver agreement. The Fisher exact test was used to compare proportions, and 1-way analysis of variance was used to compare continuous variables. The Light $\kappa$ coefficient was calculated to assess interrater reliability. All analyses were performed with JMP, Version 14 (SAS Institute, Cary, North Carolina), and a $P$ value $<.05$ indicated a statistically significant difference.

\section{RESULTS}

\section{Subjects}

A total of 324 orbital MR imaging examinations were reviewed with 72 examinations excluded for lack of a high-resolution axial 


\begin{tabular}{|c|c|}
\hline Study Group Characteristics & \\
\hline \multicolumn{2}{|l|}{ Sex } \\
\hline Male & $85(37 \%)$ \\
\hline Female & $143(63 \%)$ \\
\hline Age (mean) (SD) (yr) & $51.2(19.9)$ \\
\hline BMI (mean) (SD) & $27.2(6.2)$ \\
\hline \multicolumn{2}{|l|}{ Obese } \\
\hline Yes & $51(28 \%)$ \\
\hline No & $133(72 \%)$ \\
\hline \multicolumn{2}{|l|}{ Graves } \\
\hline Yes & $8(4 \%)$ \\
\hline No & $220(96 \%)$ \\
\hline \multicolumn{2}{|l|}{ Hypercortisolism } \\
\hline Yes & $12(5 \%)$ \\
\hline No & $216(95 \%)$ \\
\hline \multicolumn{2}{|l|}{ Prior orbital trauma } \\
\hline Documented & $3(1 \%)$ \\
\hline None documented & $225(99 \%)$ \\
\hline \multicolumn{2}{|l|}{ Globe position } \\
\hline Normal & $397(87 \%)$ \\
\hline Proptosis & $37(8 \%)$ \\
\hline Enophthalmos & $22(5 \%)$ \\
\hline \multicolumn{2}{|l|}{ Indication (No.) } \\
\hline Diplopia & 41 \\
\hline Vision changes/loss/field cut & 32 \\
\hline Mass & 28 \\
\hline Optic neuropathy & 14 \\
\hline Papilledema & 11 \\
\hline Optic neuritis & 10 \\
\hline Various other & 92 \\
\hline
\end{tabular}

Note:-BMI indicates body mass index.

${ }^{\mathrm{a}} \mathrm{BMI}$ information was not available for $n=44$.

T1-weighted sequence through the orbits without gadolinium contrast, 22 examinations excluded because of a prior orbital operation, and 2 examinations excluded because an orbital MR imaging examination from the same patient was already included in the study cohort. This yielded 228 patients who met the inclusion criteria of this study.

Patient age, sex, body mass index, Graves disease, hypercortisolism, prior orbital trauma, globe position, and study indication data are provided in the Table.

\section{Reader Assessment}

Interobserver agreement was $90.4 \%$ among the 3 readers for the presence or absence of orbital fat prolapse (206 patients without discrepancy, 22 patients with discrepancy). The Light $\kappa$ coefficient was 0.65 , indicating "good" agreement.

Prolapse of orbital fat into the infratemporal fossa via the inferior orbital fissure was observed in 20 patients (9\%) ranging in age from 25 to 79 years. This finding was unilateral in 11 patients (55\%) and bilateral in 9 patients (45\%). The measured long axis of prolapsed fat ranged from 2 to $14 \mathrm{~mm}$ (mean, $7 \pm 3 \mathrm{~mm}$ ).

Among instances of prolapsed orbital fat, associated septa were present in $69 \%$, faintly increased fluid signal was present in $26 \%$, and faint enhancement was seen in $8 \%$. There was no statistically significant association between orbital fat prolapse and age $(P=.44)$, sex $(P=1.00)$, obesity $(P=.52)$, Graves disease $(P=$ 1.00), hypercortisolism $(P=.07)$, prior orbital trauma $(P=1.00)$, proptosis $(P=.61$ for both right and left globes), or enophthal$\operatorname{mos}(P=.26$ for the right globe, $P=1.00$ for the left globe).

\section{DISCUSSION}

Radiologists' responsibilities include confidently differentiating normal anatomy and normal variants from disease. Although the distinction between normal anatomy and pathology is often relatively straightforward, determining that a finding represents a normal variant rather than disease can be more problematic. Misdiagnosis of normal variation as pathology can lead to unnecessary additional tests and subject the patient to potentially harmful procedures. Accordingly, textbooks ${ }^{9,10}$ and articles ${ }^{11-15}$ have been devoted to normal variants that may simulate disease. However, not infrequently, the evidence underlying the supposition that a particular finding represents a normal variant rather than pathology is anecdotal or, in some cases, altogether lacking. Because differentiating normal variants from disease is central to the work of the radiologist, we believe an evidence-based approach is worthwhile.

Numerous patterns of orbital fat prolapse have been previously described, many of which are clinically relevant. This study describes an additional pattern of orbital fat prolapse involving the inferior orbital fissure with an estimated prevalence of $9 \%$, which is more commonly unilateral. This study provides evidence in support of our hypothesis that this finding falls within the range of normal anatomic variations and is unlikely to be of clinical significance.

It is unknown whether this pattern of prolapse results from a structural anomaly of the orbit. A recent case report ${ }^{16}$ describes herniation of buccal fat into the orbit through an abnormally enlarged inferior orbital fissure and postulates that herniation was possible because of the inferior orbital fissure configuration. It remains an open question whether prolapse of orbital fat into the infratemporal fossa via the inferior orbital fissure is associated with variations in the dimensions of the inferior orbital fissure from reported norms, ${ }^{17-19}$ and this question would likely best be addressed with a future CT-based investigation.

An important limitation of this study is that a restricted number of possible pathologic associations were tested. An additional limitation is that the electronic medical record was used to determine the presence or absence of the diseases of interest. Relevant documentation could be incomplete or inaccurate, and it is also possible that relevant information was overlooked during our search. Although the literature informed the tested pathologic associations in this study, it is possible that a pathologic association that was not tested exists. Statistical testing for additional associations outside those supported by the literature could be performed but would also increase the risk of a type I error in this relatively small cohort. Future studies of larger cohorts testing additional possible associations could mitigate the theoretic risk of a true pathologic association not detected by the current study.

\section{CONCLUSIONS}

Prolapse of orbital fat into the infratemporal fossa via the inferior orbital fissure is a relatively common finding on orbital MR imaging that is likely a normal anatomic variant of no clinical significance. It is important for practicing neuroradiologists to recognize this finding so as not to mistake it for a pathologic entity, such as a mass. 
Disclosures: Hillary R. Kelly_UNRELATED: Royalties: Elsevier, Comments: Book royalties were earned as editor of textbook on neuroradiology and head and neck radiology.

\section{REFERENCES}

1. Birchall D, Goodall KL, Noble JL, et al. Graves ophthalmopathy: intracranial fat prolapse on CT images as an indicator of optic nerve compression. Radiology 1996;200:123-27 CrossRef Medline

2. Lin CC, Liao SL, Liou SW, et al. Subconjunctival herniated orbital fat mimicking adipocytic neoplasm. Optom Vis Sci 2015;92:1021-26 CrossRef Medline

3. Cellina M, Floridi C, Panzeri M, et al. The role of computed tomography $(\mathrm{CT})$ in predicting diplopia in orbital blowout fractures (BOFs). Emerg Radiol 2018;25:13-19 CrossRef Medline

4. Takahashi Y, Nishimura K, Kakizaki H. Orbital fat prolapse into the nasal cavity in orbital blowout fracture. J Craniofac Surg 2016;27: e615-17 CrossRef Medline

5. Tong L, Qian J, Adam R. Bilateral orbital lymphoma presenting as recurrence of orbital fat pad after blepharoplasty. Can J Ophthalmol 2017;52:e9-11 CrossRef Medline

6. Chatzistefanou KI, Samara C, Asproudis I, et al. Subconjunctival orbital fat prolapse and thyroid associated orbitopathy: a clinical association. Clin Interv Aging 2017;12:359-66 CrossRef Medline

7. Peyster RG, Ginsberg F, Silber JH, et al. Exophthalmos caused by excessive fat: CT volumetric analysis and differential diagnosis. AJR Am J Roentgenol 1986;146:459-64 CrossRef Medline

8. Forrest C. Secondary management of posttraumatic craniofacial deformities. In: Weinzweig J, ed. Plastic Surgery Secrets. 2nd ed. Philadelphia: Mosby/Elsevier;2010:330-39
9. Keats TE, Anderson MW. Atlas of Normal Roentgen Variants That May Simulate Disease. Philadelphia: Elsevier/Saunders; 2013

10. Bancroft LW, Bridges MD, eds. MRI Normal Variants and Pitfalls. Philadelphia: Wolters Kluwer Health/Lippincott Williams and Wilkins; 2009

11. Helms CA, Sims R. Foraminal spurs: a normal variant in the lumbar spine. Radiology 1986;160:153-54 CrossRef Medline

12. Shpilberg KA, Daniel SC, Doshi AH, et al. CT of anatomic variants of the paranasal sinuses and nasal cavity: poor correlation with radiologically significant rhinosinusitis but importance in surgical planning. AJR Am J Roentgenol 2015;204:1255-60 CrossRef Medline

13. Motamedi D, Everist BM, Mahanty SR, et al. Pitfalls in shoulder MRI: Part 1, normal anatomy and anatomic variants. AJR Am J Roentgenol 2014;203:501-07 CrossRef Medline

14. Earwaker J. Anatomic variants in sinonasal CT. Radiographics 1993; 13:381-415 CrossRef Medline

15. Welker KM, DeLone DR, Lane JI, et al. Arrested pneumatization of the skull base: imaging characteristics. AJR Am J Roentgenol 2008; 190:1691-96 CrossRef Medline

16. Aldridge T, Thomson A, Ilankovan V. Abnormal anatomy of inferior orbital fissure and herniation of buccal fat pad. Br J Oral Maxillofac Surg 2015;53:92-93 CrossRef Medline

17. De Battista JC, Zimmer LA, Theodosopoulos PV, et al. Anatomy of the inferior orbital fissure: implications for endoscopic cranial base surgery. J Neurol Surg B Skull Base 2012;73:132-38 CrossRef Medline

18. Turvey TA, Golden BA. Orbital anatomy for the surgeon. Oral Maxillofac Surg Clin N Am 2012;24:525-36 CrossRef Medline

19. Ozer MA, Celik S, Govsa F. A morphometric study of the inferior orbital fissure using three-dimensional anatomical landmarks: application to orbital surgery. Clin Anat 2009;22:649-54 CrossRef Medline 